\title{
Impact of COVID-19 pandemic on postpartum contraception services in women delivering at a tertiary care centre in South India
}

\author{
Parvathi T. Naik ${ }^{1}$, Sujithra D. Radhakrishnan ${ }^{1 *}$, Rupesh B. Murugan ${ }^{1}$, Haritha Sagili', \\ Subitha Lakshminarayanan ${ }^{2}$, Priyadarshini Muruganandhan ${ }^{1}$, \\ Aishwarya T. Puliyullaveettil ${ }^{1}$, Sathish Rajaa ${ }^{2}$
}

\begin{abstract}
${ }^{1}$ Department of Obstetrics and Gynecology, ${ }^{2}$ Department of Preventive and Social Medicine, JIPMER, Pondicherry, India
\end{abstract}

Received: 18 September 2021

Revised: 30 September 2021

Accepted: 01 October 2021

*Correspondence:
Dr. Sujithra D. Radhakrishnan,
E-mail: sujiradjan@gmail.com

Copyright: (C) the author(s), publisher and licensee Medip Academy. This is an open-access article distributed under the terms of the Creative Commons Attribution Non-Commercial License, which permits unrestricted non-commercial use, distribution, and reproduction in any medium, provided the original work is properly cited.

\begin{abstract}
Background: Contraception and sexual health are a fundamental human right and an integral part of women's health services. Postpartum period is the unique opportunity for counselling and availing contraception. COVID-19 pandemic hindered routine and special services like postpartum clinics has negative impact on family planning services. Objectives were to assess the effect of the COVID-19 pandemic on postpartum contraceptive care services received and to describe the challenges faced in availing these services among pregnant women delivering at a tertiary care centre in South India.

Methods: A descriptive study carried out in 422 women who had delivered at our hospital from July 2020 to October 2020. Data was collected in Epicollect version 5 and analysed using Stata version 14.2.

Results: A total of 422 women were interviewed. Only one-third of the participants received contraceptive counselling in the antenatal period compared to $90 \%$ postpartum. 39\% (primiparous-34\%/multiparous-5\%) had adopted barrier methods followed by post-partum intrauterine uterine contraceptive devices in 33\% (primiparous-19.6\%/multiparous$13.4 \%$ ) and $5 \%$ had sterilisation concurrent with caesarean section. Around 30-40\% of women faced challenges in accessing the family planning methods due to closure of elective services like postpartum clinics, operation theatres, nationwide lockdown, and non-availability of field health workers.

Conclusions: Contraceptive choices for postpartum women appear to be largely restricted to temporary methods with additional challenges of availing these services during the pandemic. With the ongoing COVID-19 crisis and continuous need for contraception, there is a need to refocus and motivate eligible couples for long-acting reversible contraceptive methods (LARC) with significantly lower failure rates.
\end{abstract}

Keywords: COVID-19, Contraception services, Postpartum, Challenges

\section{INTRODUCTION}

World Health Organisation (WHO) announced the COVID-19 outbreak as a pandemic on 11 March 2020 and India entered a nationwide lockdown on 25 March $2020 .{ }^{1}$ Essential health services in India have been majorly disrupted both in the public and private sector during the lockdown, and the health system has been slow to recover while coping with COVID-19 care. Unfortunately, four phases of lockdown and five phases of unlock during first wave of pandemic have forced several elective health services to shut down limiting the provision of contraceptive services. Special services such as postpartum clinics and postpartum operative facilities, 
essential for follow-up of women receiving contraceptive services have been non-functional due to the COVID-19 pandemic. A similar health care crisis was reported in the West African Ebola outbreak in 2013-2016. ${ }^{2}$ Closure of interstate borders not only affected the health care needs but also the import, supply chains and, access to the contraceptive services fuelling the crisis. ${ }^{3}$

There are lack of studies addressing the effect of the COVID-19 pandemic on postpartum contraceptive services and the challenges faced by postpartum women availing these services in India. This study was carried out to assess the effect of the COVID-19 pandemic on contraception care services received during the pandemic and to describe the challenges faced in availing these services among pregnant women delivering at a tertiary care centre in South India.

\section{METHODS}

This was a descriptive, cross-sectional study conducted from July 2020 to October 2020 in a tertiary care hospital Puducherry, South India. Monthly around 1200-1500 vaginal deliveries and 350-400 caesarean sections are performed accounting for total deliveries of approximately 1600-1900; 180-215 tubectomies and 75-90 intra-uterine contraceptive devices (IUCD) insertions are done on an average. However, during COVID-19 pandemic, all routine services were shut down for a period of 8 months with closure of elective operation theatres. Teleconsultation services were initiated to fix appointments and for follow up of non-emergency conditions.

The protocol for the research project was approved by institute scientific advisory committee and ethics committee and it confirms to the provisions of the declaration of Helsinki. Pregnant women aged 18 years and above who had delivered at our hospital during the study period were included in the study. The contact details of patients were obtained from the confinement register in the labour room. Approximately 20 deliveries were being conducted daily and about five women were chosen by simple random sampling from the daily list. Random numbers were generated using Microsoft excel. Due to relative lack of estimates, sample size calculation was based on the assumption that $50 \%$ of women have received contraceptive services during the COVID pandemic phase. With absolute precision of $5 \%$, confidence level of $95 \%$ frequency in a population, using Openepi software version 3.0 the initial estimate was 384 . After a corrected estimate (considering non-response of $10 \%$ ) the final sample size was calculated to be 422 .

Women were contacted via telephonic call by the principal/co-investigator. Verbal telephonic consent was recorded following which the questionnaire was administered by the investigator to collect the data inputs regarding the various contraception care services. The questionnaire was piloted and modifications were done accordingly. Age, parity, place, socio-economic status, and clinical details were noted. Type of contraceptive usage and the challenges faced in accessing these services were collected. Responses were entered in Epicollect Version 5 and data was analysed using Stata version 14.2 (StataCorp, College Park, TX, USA). Continuous variables were expressed as mean (SD) and categorical variables were expressed as proportions.

\section{RESULTS}

A total of 422 participants who were contacted and response rate was $100 \%$. Two- thirds of the subjects $(n=301,71.3 \%)$ were primiparous and $121(28.7 \%)$ were multiparous. The majority of our study population were graduates and belonged to lower/ upper-lower socioeconomic class (Table 1). Three hundred and three $(71.8 \%)$ of these pregnant women who had delivered from July 2020 to October 2020 had directly reported to our emergency medical services and 119 (28.2\%) were referred from other centres. Majority of them 395 (93.6\%) reached our centre by private transport at their own expense and $27(6.4 \%)$ had availed the Government ambulance (108) services. Based on risk categorization, 137 were classified as high-risk pregnancies accounting for $32.5 \%$.

Table 1: Socio-demographic and clinical characteristics of the study population $(n=422)$.

\begin{tabular}{|c|c|c|}
\hline Characteristics & $\mathrm{n}=\mathbf{4 2 2}$ & Percentage $(\%)$ \\
\hline \multicolumn{3}{|l|}{ Age (years) } \\
\hline $18-35$ & 409 & 96.9 \\
\hline$>35$ & 13 & 3.1 \\
\hline \multicolumn{3}{|l|}{ Education } \\
\hline No formal education & 1 & 0.2 \\
\hline Primary & 9 & 2.2 \\
\hline High school & 85 & 20.2 \\
\hline Higher secondary & 109 & 25.8 \\
\hline Graduate & 218 & 51.6 \\
\hline \multicolumn{3}{|l|}{ Socio-economic class* } \\
\hline Upper/upper middle & 14 & 3.3 \\
\hline Middle & 174 & 41.3 \\
\hline Lower/upper lower & 234 & 55.4 \\
\hline \multicolumn{3}{|c|}{ Nearest health center (min) } \\
\hline$<30$ & 412 & 97.6 \\
\hline$\geq 30$ & 10 & 2.4 \\
\hline \multicolumn{3}{|c|}{ Distance from our center $(\mathrm{km})$} \\
\hline$<50$ & 290 & 68.7 \\
\hline $50-100$ & 71 & 16.8 \\
\hline$>100$ & 61 & 14.5 \\
\hline \multicolumn{3}{|l|}{ Parity index } \\
\hline Primiparous & 301 & 71.3 \\
\hline Multiparous & 121 & 28.7 \\
\hline \multicolumn{3}{|l|}{ Mode of delivery } \\
\hline Vaginal & 305 & 72.3 \\
\hline Cesarean & 117 & 27.7 \\
\hline
\end{tabular}

* Modified BG Prasad classification $2020^{4}$ 
Table 2 depicts the contraceptive services availed by the participants of our study. Approximately only one-third had received contraceptive counselling in the antenatal period either during teleconsultation or in-person visits by a doctor or public health worker providing antenatal care. A majority $(n=302,90 \%)$ of the women who had delivered in our hospital had received postpartum contraceptive advice. The remaining ten percent of women failed to receive postnatal contraceptive advice due to the diversion of human resources to pandemic management. Threefourths $(n=327,77.4 \%)$ women had adopted a contraceptive method; $81 \%$ among primiparous and $69 \%$ among multiparous women. IUCD was used in one-third of primiparous and multiparous women. Overall, only 20 (16.5\%) of multiparous had undergone tubectomy along with caesarean section.

The challenges faced by women who had delivered in our study are summarised in Table 3. A substantial proportion (30 to $40 \%$ ) of the pregnant women who had delivered in our hospital faced significant problems in accessing the contraceptive services due to lockdown and closure of special clinics (postpartum) and operation theatres for elective procedures like sterilization (puerperal/interval) at our centre and also nearby health facilities.

Table 2: Contraceptive services availed among the study population $(n=422)$.

\begin{tabular}{|llll|}
\hline Characteristics & Primiparous $(\mathbf{n = 3 0 1})(\%)$ & Multiparous $(\mathbf{n = 1 2 1})(\%)$ & Overall $(\mathbf{n = 4 2 2})(\%)$ \\
\hline Contraceptive counselling & & $54(44.6)$ & $150(35.6)$ \\
\hline Antenatal period & $96(31.9)$ & $111(91.7)$ & $381(90.3)$ \\
\hline Postpartum period & $270(89.7)$ & $38(31.4)$ & $95(22.5)$ \\
\hline Contraceptive usage & & $83(68.6)$ & $327(77.5)$ \\
\hline Non-users & $57(19.0)$ & & $166(39.3)$ \\
\hline Users & $244(81.0)$ & $21(17.4)$ & $141(33.4)$ \\
\hline Contraceptive methods & $145(48.1)$ & $42(34.7)$ & $15(10.7)$ \\
\hline Barrier & $99(32.9)$ & 5 & $126(89.3)$ \\
\hline Intrauterine contraceptive device & 10 & 37 & $20(4.7)$ \\
\hline Intra-caesarean & 89 & $20(16.5)$ & $95(22.5)$ \\
\hline Postpartum & 0 & $38(31.4)$ & \\
\hline $\begin{array}{l}\text { Concurrent tubectomy with } \\
\text { caesarean section }\end{array}$ & $57(19.0)$ & & \\
\hline Non users & & & \\
\hline
\end{tabular}

Table 3: Challenges faced in accessing contraceptive services among the study population $(\mathrm{n}=422)$.

\begin{tabular}{|lll|}
\hline Challenges & n & $\%$ \\
\hline Access to field health care workers & 175 & 41.4 \\
\hline Closure of nearest health facility (private) & 146 & 34.6 \\
\hline Fixing teleconsultation appointment & 143 & 33.8 \\
\hline Travel to health center/hospital & 145 & 34.4 \\
\hline Procuring contraceptive methods & 139 & 32.9 \\
\hline
\end{tabular}

\section{DISCUSSION}

The COVID-19 pandemic has paralyzed the global health care services, and it's devastating impact on the economic state may add to the burden of unwanted pregnancies in midst of unemployment and shortage of essential commodities in many countries especially more on lowand middle-income countries (LMICs) like India. Contraception and sexual health are a fundamental human right and an integral part of essential health services making it a priority not only during a pandemic but also in routine women's health services. ${ }^{5}$ Three delays i.e. delay in seeking, accessing, and receiving contraception during a pandemic may increase the risk of maternal mortality or morbidity secondary to unwanted pregnancies, and an increased financial burden of tackling these complications by an already strained health care system.

In our study, only $150(35.6 \%)$ of women received contraceptive counselling in their antenatal period despite the majority $412(97.6 \%)$ having a nearest health facility within 30 minutes of travel time. Most $(34.6 \%)$ of the women expressed closure of health centers and restricted appointments for in-person visits to maintain social distancing as major hindering factors.

In January 2013, the Government of India defined quality postpartum care as one of the important components under reproductive, maternal, newborn, child and adolescent health $(\mathrm{RMNCH}+\mathrm{A}){ }^{6} \quad$ Postpartum care includes 
contraception, lactation support, and three postnatal visits. Given the severe acute respiratory syndrome coronavirus 2 (SARS-CoV2) infection and the nationwide lockdowns causing severe hindrances for the well-being of people, the methods of delivering health services have drastically changed even though the needs of the sexual and reproductive health of women have remained the same. During the pandemic to aid this task, various comprehensive guidelines have been issued by international federation of gynaecology and obstetrics (FIGO), faculty of sexual and reproductive healthcare (FSRH) and Royal college of obstetricians and gynaecologists (RCOG), WHO and centers for disease control and prevention (CDC) to guide clinicians for continued contraceptive services. ${ }^{5,7}$ To help the obstetricians in India, foundation for reproductive health services India has provided guidance relevant to our population. ${ }^{10}$ As the postpartum period is the only opportunity in LMIC's for counselling and availing contraception during the pandemic, all the recommendations suggested are focused on LARC in the form of post-partum intra-uterine contraceptive device (PPIUCD), implants, and depot medroxy-progesterone acetate (DMPA). Also, self-care family planning methods need to be promoted with supply for continuous usage for adherence. In addition to the above recommendation, the key point would be to address the barrier for accessing contraception by task shifting to well-trained midwives or public health nurses for providing these services to women herself. Liberalisation of over-the-counter prescriptions following safety norms can also aid the process. These facilities can be reinforced by the utilisation of digital health tools to reach women's doorstep and encourage them to avail contraception without visiting crowded health care facilities.

The total unmet need in contraception in our country is as high as $13 \%$, out of which $6 \%$ were for spacing and $7 \%$ for limiting the births. This unmet need is mainly due to the lack of skilled service providers at peripheral health facilities. ${ }^{11}$ A recent systematic review and meta-analysis by Dev et al reported moderate contraceptive use (20-40\%) in LMIC's and increased need of contraception for spacing and limiting pregnancy with regard to postpartum contraception. ${ }^{12}$ According to national family health survey (2015-16), the methods of contraception used by Indian women were sterilisation $(36 \%)$, the rhythm method $(3.5 \%)$, condoms $(5.6 \%)$, pills $(4.1 \%)$, and IUCD $(1.5 \%)^{11}$ During the COVID-19 pandemic, we observed that there was a paradigm shift in contraceptive choices with approximately 39\% adopting barrier methods followed by PPIUCD (33\%) and sterilisation in only $5 \%$. Also, there was a fivefold and sixteen-fold increase in the acceptance of condoms and IUCD respectively, and a seven-fold reduction in permanent methods due to closure of elective services; only women undergoing caesarean section could get the benefit of sterilization.

In our study among 301 primiparous women, 99 (32.9\%) had IUCD inserted following delivery. More than two- thirds of multiparous women who had delivered vaginally said that although they had wanted a permanent method of contraception in the postpartum period i.e. puerperal sterilization; instead had to opt for LARC in the form of PPIUCD (34.7\%). The acceptance for LARC though comparable among primiparous and multiparous women, is only found in one-third of the subjects, and around $90 \%$ of these insertions have been during the postpartum period. In our study, $145(48.1 \%)$ primiparous women and 21 (17.4\%) of multiparous women opted for barrier methods. One-fifth of primiparous and one-third of multiparous women had not adopted any contraceptive methods adding the risk of unplanned pregnancies and their associated complications. It is essential that they are covered through the primary care system by home delivery of contraceptives or counselling for following up on DMPA or interval IUCD insertions. Counselling needs to be focussed from the antenatal period or through teleconsultation to change their mindset from the routine services like tubectomy to these newer methods. Later, women willing for permanent methods should be identified and referred to the secondary and tertiary centres once routine hospital services reopen on a priority basis.

About one-third of the participants faced challenges for accessing family planning services due to restricted mobility because of fear of acquiring the infection with an in-person visit to the health centre. These challenges were further worsened by network connectivity issues for utilization of the telemedicine facilities. There was an additional burden of expenditure towards transportation by private vehicles due to the limited availability of public transport facilities during the COVID-19 crisis.

Most of the available literature has projected the impact of the pandemic on contraceptive and family planning services. Our study has attempted to find the real impact in a hospital-based setting among postpartum women. Limitations of the study are the retrospective nature and the findings might not reflect the population at large. Due to telephonic-based interview, most women could not spare enough time from their domestic responsibilities and some had recall issues regarding the challenges faced.

In the era of social media and technological advances, virtual consultation, education on reproductive health, and contraception counselling services using teleconsultation via mobile phones (instant messaging) in countries with high COVID-19 burden would facilitate the continuity of these services. ${ }^{4}$ There is an urgent need for the Government and national policymakers to advocate longacting reversible contraceptive methods (PPIUCD/DMPA) and reposition them as an effective alternative for sterilisation which had been the preferred contraceptive method in the pre-pandemic era. Behavioural change, communication through mass media and social media campaigning may be beneficial for women and also to sensitise the decision makers like spouses and other family members. To fill the lacunae created by the pandemic; there appears to be a need for 
shifting of contraceptive services from clinics to the community by involving trained field health care workers and educating women regarding self-care family planning methods. ${ }^{6}$ With the ongoing COVID-19 crisis and continuous need for contraception, these services can further be widened with partnership of the private health sector for adequate coverage of contraceptive services to eligible couples.

\section{Strengths of study}

Most of the available literature has projected the impact of the pandemic on contraceptive and family planning services. Our study has attempted to find the real impact in a hospital-based setting among postpartum women.

\section{Limitations}

The retrospective nature and the findings might not reflect the population at large. Due to telephonic-based interview, most women could not spare enough time from their domestic responsibilities and some had recall issues regarding the challenges faced.

\section{CONCLUSION}

Contraceptive choices for postpartum women appear to be largely restricted to temporary methods with additional challenges of availing these services during the pandemic. With the ongoing COVID-19 crisis and continuous need for contraception, there is a need to refocus and motivate eligible couples for LARC with significantly lower failure rates.

Funding: No funding sources

Conflict of interest: None declared

Ethical approval: The study was approved by the Institutional Ethics Committee

\section{REFERENCES}

1. World Health Organisation. Director-General's opening remarks at the media briefing on COVID-19. Available at: https://www.who.int/directorgeneral/speeches/detail/who-director-general-sopening-remarks-at-the-media-briefing-on-covid-19--11-march-2020. Accessed on 11 March 2020.

2. Bietsch K, Williamson J, Reeves M. Family Planning During and After the West African Ebola Crisis. Stud Fam Plann. 2020;51(1):71-86.

3. UNFPA. Sexual and Reproductive Health and Rights: Modern Contraceptives and Other Medical Supply Needs, Including for COVID-19 Prevention, Protection and Response. Available at: https://www.unfpa.org/sites/default/files/resourcepdf/COVID-19_Preparedness_and_Response_ UNFPA_Interim_Technical_Briefs_Contraceptives_ and_Medical_Supplies_23_March.pdf. Accessed on 10 July 2021.

4. Debnath DJ. Kakkar R. Modified BG Prasad Socioeconomic Classification, Updated - 2020. Indian J Comm Health. 2020;32(1):124-5.

5. FIGO. FIGO Committee on Contraception and Family Planning statement on COVID-19 and pregnancy. Available at: https://www.figo.org/covid-19contraception-family-planning. Accessed on 12 July 2021.

6. RMNCH+A. A Strategic approach to reproductive, maternal, new born, child and adolescent health $(\mathrm{RMNCH}+\mathrm{A})$ in India. Available at: https://nhm.gov.in/images/pdf/RMNCH+A/RMNCH +A_Strategy.pdf. Accessed on 12 July 2021.

7. FSRH, RCOG, and RCM. Guidance on the provision of contraception by maternity services after childbirth during the COVID-19 pandemic. Available at: https://www.rcog.org.uk/globalassets/documents/gui delines/2021-02-guidance-on-the-provision-ofcontraception-by-maternity-services-after-childbirthduring-the-covid-19-pandemic.pdf. Accessed on 15 July 2021.

8. World Health Organization. Maintaining essential health services: operational guidance for the COVID19 context: interim guidance. Available at: https://apps.who.int/iris/handle/10665/332240. Accessed on 17 July 2021.

9. Centers for Disease Control and Prevention. Ensuring access to family planning services during COVID19: A summary of CDC's family planning recommendations for healthcare providers. Available at: https://www.cdc.gov/reproductivehealth/contrace ption/pdf/FP-and-Covid-19-Fact-Sheet_Final.pdf. Accessed on 17 July 2021.

10. Foundation for Reproductive Health Services India. Impact of COVID 19 on India's Family Planning Program. Available at http://www.frhsi.org.in/pdf/ impact-of-covid-19-on-indias-family-planningprogram-policy-brief.pdf. Accessed on 17 July 2021.

11. International Institute for Population Sciences (IIPS) and ICF. 2017. National Family Health Survey (NFHS-4), 2015-16: India. Mumbai: IIPS. Available at http://rchiips.org/nfhs/NFHS4Reports/India.pdf. Accessed on 17 July 2021.

12. Dev R, Kohler P, Feder M, Unger JA, Woods NF, Drake AL. A systematic review and meta-analysis of postpartum contraceptive use among women in lowand middle-income countries. Reprod Health. 2019;16(1):154.

Cite this article as: Naik PT, Radhakrishnan SD, Murugan RB, Sagili H, Lakshminarayanan S, Muruganandhan P, et al. Impact of COVID-19 pandemic on postpartum contraception services in women delivering at a tertiary care centre in South India. Int J Reprod Contracept Obstet Gynecol 2021;10:4392-6. 